AUTOR

\section{Juan Bautista}

Lucca*

juanlucca@

hotmail.com

\title{
Los Sertones, o la construcción del Brasil en la obra de Euclides da Cunha
}

\author{
Os Sertões, ou a construção do Brasil na obra de Euclides da Cunha
}

The backlands, or the construction of Brazil in Euclides da Cunha's work

\section{RESUMEN}

Elpresenteartículotienecomoobjetivocentralrecuperarlalecturadeunodelosprincipalesexponentes delensayismobrasileño(EuclidesdaCunha)apartirdesuobranodal("Lossertones")paradesentrañar la morfología que adquiere la construcción de la nación brasileña en el viraje del siglo XIXy XX en la pluma de uno de los principales literatos de la naciente República Federativa de Brasil.

A tal fin, la propuesta analítica de este escrito radica en desandar dos dimensiones para abordar la complejidaddelapropuestadelperiodista:porunlado,tomarencuentalasaristasqueofreceeltexto paraconstruirunespacio-tiempocondensidadantropológicaypolíticaqueelautorllamaSertón;y, por el otro, analizar la múltiple y extensa intertextualidad que ofrece esta obra en sí, pero también comolaproducción deDaCunhareverberaenotrosexponentes delaliteraturacomoD. F.Sarmiento, J. Guimarães Rosa, M. Vargas Llosa o G. Freyre.

\section{RESUMO}

EsteartigotemoobjetivoderecuperaraleituradeumdosprincipaisexpoentesdaliteraturaBrasileira(Euclidesda Cunha)eseutrabalhocentral("OsSertões")paraobservaramorfologiaqueadquireaconstruçãodanaçãobrasileira no fim do séculoXIXeinicio do XXna obra de um dos maiores escritores da nascente República Federal do Brasil. Paraestefim, otrabalho propõeduas vias deanálise paralidarcomacomplexidade da propostadojornalista:por umlado, terem contacomooautorconstróiumespaço-tempocomadensidadeantropológicaepolíticachamado sertão:e,poroutro, analisaraextensaintertextualidadeque ofereceolivrodedaCunhaemsi, mastambémcomo ele reaprecee dialoga na obra de outros autores como da D. F. Sarmiento,J.Guimarães Rosa, M. Vargas Llosa ou G. Freyre.

\section{ABSTRACT}

This articleaimstorecover the reading of one of theleadingexponents of Brazilianliterature(EuclidesdaCunha) fromhiscrucialwork("Thebacklands").Italsoaimstodiscover themorphologythatacquires the construction of the Braziliannationin the turn of thenineteenthand twentiethcentury trough the pen of one of the majorwriters of the nascent Federal Republic of Brazil.

Tothisend, the analytical proposal of this paperliesin retracing two dimensions toaddress the complexity of the proposalof thejournalist:first, takeintoaccounthowdaCunhabuilds(withpoliticalandanthropologicaldensity) thoseplacehecalls"thebacklands"; and,second, analyzetheextensiveinter-textuality thatoffersthisworkbyitself, butalsohowthisdaCunha'sworkreverberatesinotherexponents of theliteraturelikeD.F.Sarmiento,J.Guimarães Rosa, M. Vargas Llosa or G. Freyre. 
Durante miles y miles de años, el inmenso territorio del Brasil, con sus rumorosas selvas de un verde oscuro, sus montañas y ríos y su mar, de sonoro y rítmico vaivén yace ignorado y anónimo. "Brasil". Stefan Zweig (1942).

\section{El texto}

Tal y como lo señala el epígrafe de este escrito, muchas veces la atracción sobre Brasil radica en que es un territorio tan heterogéneo como desconocido, tan fértil como virgen, tan inmenso como recóndito; sin embargo, hasta la misma descripción de un viajero austríaco que se dispone a descubrir y adjetivar este país continental se olvida de aquellos rincones donde impera la soledad pero todo se encuentra abrazado por el sol, donde todo es inmovilidad o quietud porque la vida se escurre tras una grieta, donde el hombre es tan pétreo como la piedra alimento para la sed. Y en la búsqueda por desentrañar las huellas de esta ignota región desértica de Brasil, pero también de hilvanar la compleja madeja de los problemas brasileños en torno a la configuración del Estado y de la Nación, del ser brasileño como del ser sertanejo, es que aparece en 1902 la obra cumbre de Euclides Da Cunha Los Sertones [Os Sertões].

A primera vista, este libro retrata las impresiones periodísticas, científicas y ensayísticas de Euclides Da Cunha en torno a la rebelión en la ciudad de Canudos encabezada por Antonio Vicente Mendes Maciel, conocido como "El consejero" o "Antonio Consejero". En este perdido terruño del nordeste brasileño, Antonio Consejero logró convocar alrededor de 8000 seguidores o fieles y convertir a esta ciudad (fundada en 1883) en la segunda ciudad más poblada del estado de Bahía, con casi 25000 pobladores, planteando una reacción desde el principio de comunidad al advenimiento de la sociedad, una interpelación desde la fe y la tradición al desembarco de la ley y la modernidad, una anteposición desde la caridad al cobro de impuestos. Hicieron falta cuatro expediciones militares y alrededor de 10000 soldados de la naciente República Federativa de Brasil establecida en 1889 para enfrentar durante todo un año a los fieles de Canudos y finalmente aniquilar a todos los seguidores de Antonio Consejero cerca del morro de la Favela.

Uno de los espectadores presenciales de este enfrentamiento final en el año 1897 es Euclides Da Cunha, ingeniero militar formado en la Escola Militar da Praia Vermelha en la ciudad de Río de Janeiro, enviado a Canudos como corresponsal de la Gaceta de San Pablo. Aunque sus reportajes coyunturales como periodista denostaban a los fanáticos religiosos que seguían a Antonio Consejero y hacía gala de la necesidad de modernizar la región mirando con simpatías la empresa del nuevo Estado republicano, tal vez por presenciar la barbarie y escalada de violencia utilizada para poner fin a la rebelión, o tal vez por el desarrollo de una querencia sosegada hacia la región del sertón, en el momento de publicar Los Sertones en 1902, Da Cunha hace de su obra el "J'accuse" brasileño a la modernidad que encarnaba el nuevo estado, al decir:"...aquella campaña recuerda un reflujo hacia el pasado. Y fue, en la significación integral de la palabra, un crimen. Denunciémoslo" (Da Cunha, 2012: 25-26).

Ahora bien, para llevar adelante esta tarea Da Cunha no construye un ensayo de fácil lectura, de amplia circulación y de lenguaje simple o directo. En cambio, construye un texto abigarrado de casi 500 páginas en el que -fiel a los parámetros de su época- se entrecruzan cavilaciones estrictas y ávidas de ciencia en torno a "La tierra", "El Hombre" y "La lucha”, que son los tres apartados en los que se estructura este libro. En el primero, Da Cunha realiza de forma erudita una descripción minuciosa de las características geográficas y ecológicas de esta región desértica en el estado de Bahía, aunque cabe destacar que es posible encontrar también muchas sutilezas literarias y párrafos donde quedan en evidencia las impresiones personales del corresponsal, por ejemplo 
cuando inicia la sección Impresiones personales con la frase "es un paisaje impresionante", o cuando tiene que describir la escarpada orografía del lugar con expresiones como "es una sugestión dominadora", o cuando tiene que referirse a la fauna con frases como "el desierto es un paraíso" (Da Cunha, 2012:37,39 y 57 respectivamente).

En el segundo apartado, Da Cunha realiza un esfuerzo por caracterizar al hombre del sertón (sertanejo) y al mismo tiempo dar cuenta del problema etnológico de Brasil, a partir del entrecruzamiento de miradas ancladas (no siempre convergentes) en un determinismo meseológico como las del apartado I y un determinismo biológico como las de este segundo apartado, especialmente evidente en expresiones como "Nuestra evolución biológica reclama la garantía de la evolución social. Estamos condenados a la civilización. O progresamos o desaparecemos" (Da Cunha, 2012:73). Así, Da Cunha logra apuntar el hecho de que paradojalmente no existe un "tipo antropológico brasileño" producto de la mezcla de razas que tuvo este país (el blanco, el indio guaraní y el negro bantú), sin embargo es posible distinguir por sobre los mestizos brasileños del litoral a aquellos que habitaron el sertón, habida cuenta de que son una "...raza fuerte y vieja [que] era el corazón vigoroso de nuestra nacionalidad" (Da Cunha, 2012:91).

Ahora bien, los avatares de esta población enclavada en la "Troya de Barro" - como catalogó el propio Da Cunha a los habitantes del sertón - no tuvo historiadores porque careció de lugar en la historia colonial, imperial o inclusive de la nueva república que se inicia a fines del siglo XIX. Es justamente la rebelión de Canudos en general, y el apartado "La lucha" del libro Los Sertones en particular, la primera página de un relato nacional. No en vano, la aparición de esta sección del libro se demoró 5 años, porque el autor tuvo que revisar y revertir detalladamente, por un lado, la prenoción de fanáticos-pillos-barbaros que imperaba en relación a los seguidores de Antonio Consejero en Canudos y, por el otro, ajustar y darle real forma al vínculo Estado-civilización-modernidad que se imprime al accionar de las fuerzas comandadas desde Río de Janeiro.

En este sentido, tal y como apunta Florencia
Garramuño (2012:8), esta sección del libro de Da Cunha viene a echar por tierra un sinnúmero de presupuestos en torno a los cuales se estaba tratando de construir en términos de imaginario político, la naciente república, ya que desmitifica la idea de que la rebelión de Canudos sea un dominó más en la ola de la conspiración monarquista antirrepublicana de índole global; echa por tierra también la idea de una belle époque a la brasileña que atraviesa toda el territorio, porque espacios como el sertón desentonaban claramente con esta pictórica delineada desde la mirada litoraleña del sudeste; y, por último, pone en evidencia que el progreso como dirección modernizadora había sucumbido a la primacía del orden, o de la ciencia aplicada al diseño de los cañones Krupp con que se abatió a los rebeldes en Canudos.

Sin embargo, es innegable que la obra de Da Cunha engarza y sintetiza muchas de las herencias del siglo XIX y la fe y esperanza del siglo XX, condensándolo todo en este sintagma que es el sertón. Al igual que Macondo para Gabriel García Marques o Comala para Juan Rulfo, el sertón es en Da Cunha una construcción simbólica en la que se mezcla la orografía y la etnología, pero también la lucha, la guerra y la fe. La propia palabra "Sertões" es un vocablo difícil de asir fuera del mundo nordestino o brasileño, pero a la vez inmensamente atractivo gracias a la obra de Da Cunha. Así, tal y como lo menciona en 1937 uno de los primeros traductores de Los Sertones al español, Benjamin de Garay, el significado mismo del título de esta obra es intraducible, dado que la palabra sertón no es más que "...una corrupción o mutilación del aumentativo portugués de deserto, esto es, desertao (desertón). Por ley del menor esfuerzo, tan común a todas las razas indolentes de los trópicos, el habitante del interior de Brasil redujo el vocablo desertao a sus dos últimas silabas: sertao" (Da Cunha, 2012: 24).

El sertón en la obra de Da Cunha, es un espacio de génesis, éxodo y apocalipsis; es un terreno donde nace y perece el sertanejo pero también el brasileño; es un cuadrante que puede ser pensado como un paraíso desértico de dimensiones bíblicas, pero también como una "Troya de barro de los jaguncos" donde afloran diversas épicas; es un lugar de olvido y oscuridad, de aislamiento y conservación, pero también de leyendas, profecías 
y lucha; un enclave donde se entrecruzan la "ley del can" con la ley del Estado moderno; un espacio donde surge Antonio Consejero, considerado "un gran hombre para el mal" pero también un "representante natural del medio en que nació" (Da Cunha, 2012:92-125-162). Restan solo las propias palabras de Da Cunha para poder entender cómo el sertón se nos antepone como un efervescente e inconmensurable enigma que busca un simple pero inteligente traductor.

[En el sertón] la tierra se amolda a la vida; la naturaleza fecunda elevada en la apoteosis triunfal de los días deslumbrantes y calmos, y el suelo cuajado de vegetación fantástica; saciado, irrigado de ríos que corren por los cuatro puntos cardinales. Pero esta placidez opulenta, oculta, paradójicamente, gérmenes de cataclismos que, al irrumpir, siempre con un ritmo inquebrantable en el estío, rodeados de los mismos preanuncios infalibles, caen allí con fatalidad inexorable de una ley (Da Cunha, 2012:75).

Ahora bien, esta mágica configuración del sertón, así como la creciente repercusión que tiene la obra de Da Cunha en su época y el siglo posterior, va a contramano del derrotero personal del autor, quien no solo es un ensayista a caballo del pasaje del siglo, del fin de la esclavitud y del imperio lusitano, del viraje hacia la modernidad brasileña, sino también un intelectual que carga, cual Sísifo, una pesada y denodada carga en términos personales. Da Cunha es un ser errante por caminos inciertos y derroteros trágicos, lo cual puede verse, por un lado, en su infructuosa y equivocada búsqueda vocacional, ya que a pesar de formarse como militar, anhelaba ser médico, y circunstancialmente terminó siendo un hombre de letras pero no un poeta como quería en su juventud; $y$, por el otro, este halo de desazón que envuelve a Da Cunha, tiene incidencia directa en su vida personal y afectiva, ya que su frustrado casamiento con Ana Emilia Solon Ribeiro fue el inicio de su tragedia personal, ya que será el mismísimo amante de su alejada esposa (Dilemardo de Assis) el responsable de ponerle fin a la vida de Da Cunha en 1909 (De Oliveira, 2002:529-532).

En definitiva, lo que queda claro es que desde la aparición de este texto en 1902, hasta llegar a nuestros días, Los Sertones han recorrido un extenso camino hasta convertirse en una de las obras fundamentales para comprender la formación histórica de Brasil, una referencia ineludible en el marco de la construcción de las ciencias sociales en ese país, y una de las referencias seminales del ensayismo brasileño de inicios del siglo XX que, para dar cuenta de los "problemas brasileños", entremezcló lo literario con el abordaje documental (Ortiz, 1990: 166; Candido, 2000:12).

A [obra] de Euclides da Cunha [Os sertões], que se situa como o primeiro ensaio de descrição sociográfica e de interpretação histórico-geográfica do meio físico, dos tipos humanos e das condições de existência no Brasil. Com seus defeitos e limitações, e apesar da ausência de intenção sociológica, essa obra possui o valor de verdadeiro marco. Ela divide o desenvolvimento teórico-social da sociologia no Brasil. Daí em diante, o pensamento sociológico pode ser considerado como uma técnica de consciência e de explicação do mundo, inserida no sistema sociocultural brasileiro (FERNANDES, 1977: 35).

\section{El Intertexto}

Cuando se realiza la lectura de este enrevesado y denso texto compuesto por Da Cunha, además de la complejidad entre el ser y el acontecimiento que atraviesa los tres apartados de su libro, uno de los aspectos que llama la atención es la intertextualidad que encierra (pero también que abre) esta monumental obra. Es decir, pueden rastrearse múltiples referencias, algunas de forma directa y otras solapadamente, a autores que formaron parte del mapa conceptual con el que el autor carioca se dispuso a la escritura.

En este sentido, tal vez una de estas marcas que puede verse claramente en la estructura misma de la obra, es la del historiador francés Hippolyte Taine -a quien Da Cunha cita al cierre de su nota preliminar- quien proponía analizar la historia, el arte y la política como herederas de su tiempo y condiciones, para lo cual propuso la triada "razaambiente-momento" que se espeja claramente 
en la tríada propuesta por Los Sertones "La tierraEl hombre-La lucha"(Fernández Uribe, 2003 y De Oliveira, 2002: 519).

Asimismo, es posible encontrar a lo largo de su enciclopédica obra (especialmente en la primera sección "La Tierra") múltiples referencias a autores que justifican la empresa científica y moderna que el autor trata de construir. Así, es factible hallar alusiones a exponentes como el historiador británico H. T. Buckle, autor de la obra "Historia de la civilización en Inglaterra" con fuerte repercusión en el Brasil de Da Cunha; al portugués Rocha Pitta, en tanto uno de los primeros historiadores de ese país; al científico y viajero alemán Karl Friedich Von Martius al que Da Cunha adjetiva como "ilustre" por su descripción de la topografía específica de la Sierra del Monte Santo; a sus lecturas del naturalista inscripto en la perspectiva del evolucionismo darwiniano T. Huxley; al astrónomo francés Emanuel Liais; al botánico y viajero francés SantHilaire que colabora a precisar las características singulares de la flora desértica de la región; o inclusive la referencia directa a las "Lecciones sobre la Filosofía de la Historia" de Hegel para señalar el olvido que este autor realizó al no incluir la categoría geográfica que caracteriza al sertón, sustentándose ni más ni menos que en la referencia de A. von Humboldt.

Este esfuerzo de erudición que lleva adelante Da Cunha, pareciera tener como trasfondo la voluntad de inscribir los acontecimientos y características de la región del sertón en el marco de la historia universal. Esto puede verse con evidencia en el reiterado paralelismo que el autor trata de realizar entre el sertón y las distintas referencias geográficas a lo largo del mundo, como por ejemplo cuando para señalar las dimensiones del territorio la equipara con el tamaño de Holanda, o cuando compara los capilares ríos de la región con los escasos hilos de agua que surcan la región del Sahara, o cuando parangona las "lagunas muertas" o intento de contener el agua por los pobladores del sertón como una copia imperfecta de las barreras romanas en el desierto de Túnez, e inclusive cuando traza el paralelismo entre los fósiles que se encontraron en el sertón con los hallados en Perú, México o Panamá (Da Cunha, 2012: 34-39; 36-40).

Ahora bien, esta pretensión por oficiar de antropólogo social que busca describir por primera vez los pliegues del desierto de Bahía, y al mismo tiempo realizar una crítica política a la bárbara civilización que el nuevo estado republicano quiso imponer a los sertanejos que vivían en este enclave bíblico construido por Antonio Consejero, tiene enormes paralelismos con empresas intelectuales de igual talla, como por ejemplo las que realizara el sanjuanino D.F. Sarmiento en Facundo, del cual Da Cunha ofrece testimonio de haber leído.

Entre las similitudes que ambos escritores comparten, pueden destacarse: en primer lugar, ser escritos donde se condensa el aspecto histórico, antropológico y topográfico para configurar un ensayo sobre la construcción de la nacionalidad; en segundo lugar, que ambos autores señalan que la escritura de estos textos fue una lucha heroica; en tercer lugar, que existe en ambos el interés por analizar las vicisitudes de una región atrasada como es el desierto o el sertón para encontrar allí una clave interpretativa de la historia y del presente; en cuarto lugar, que ambos comparten la fascinación por dar cuenta de los inciertos derroteros de la nación en el marco de una guerra civil; en quinto lugar, que Sarmiento y Da Cunha tienen una visión ambivalente sobre los pobladores de los sectores rurales o semi salvajes, e invisten a la figura del gaucho argentino y su homónimo brasileño de rudeza y bravura; $y$, por último, que los dos retratan el choque de dos mundos, condensados por la díada centro versus la periferia, capital versus el interior, aridez versus fertilidad, o simplemente civilización y barbarie.

Ahora bien, son innegables también las diferencias que encontramos en la comparación de ambos escritos, como por ejemplo al diferenciar los modos de vida del gaucho y del sertanejo, ya que este último coloca como su antagonista al gaúcho brasileño durante la tercera expedición al mando de Moreira Cesar; o las distancias que existen entre las dos figuras centrales de ambos ensayos (Facundo y Antonio Consejero) dado que uno es la encarnación de la ambición y la fuerza desmedida mientras que el otro es la entronización de la fe y la moral mal entendidas; o inclusive en lo que atañe al referente empírico y la significación de la civilización y de la barbarie.

Si nos detenemos en este último aspecto, a 
diferencia de Sarmiento, en Los Sertones se encuentra un esfuerzo claro por parte de Da Cunha por dejar sentada la presencia de "otra forma" de civilización y de cultura anclada en el principio de comunidad entre los sertanejos, que se antepone a la idea de civilización cosmopolita que se comenzaba a instalar en el marco de la nueva república, y de la que muchas veces el propio autor se siente ajeno (De Oliveira, 2002). En la tercera sección del libro ("La lucha"), Da Cunha muestra con vehemencia aquello que había propuesto denunciar en su "nota introductoria": la barbaridad del estado en pos de la civilización, el uso excesivo de la violencia por parte del estado en pos de su génesis como tal, la construcción de un Leviatán sobre la base de empuñar la espada y el báculo de la religión cívica. En este sentido, como propone Cecilia Garramuño, es posible encontrar en Los Sertones la evidencia de una "...barbarie típicamente moderna que se verá incluso como síntoma, como querría Norbert Elías, del proceso civilizatorio" (2012:17).

Entonces, el enfrentamiento en Canudos ya no es la puja entre la civilización y la barbarie, sino el desdibujamiento de ambos aspectos, ya que es el encuentro ni más ni menos que de dos subculturas, en donde conviven rasgos de civilización, pero también la impronta de la barbarie. En este sentido, los sertanejos son los homónimos de los militares republicanos que construyen la nación brasileña a sangre y fuego; sin embargo, paradojalmente, únicamente al morir los sertanejos a manos de los militares habrán ambos de compartir el destino de ser finalmente llamados brasileños, y en este mismo hecho los militares no podrán escapar del estigma de saber que - parafraseando a Guimarães Rosadesde entonces en la historia de la nación brasileña "el sertón está dentro nuestro" (Sena, 1998:20).

Ahora bien, más allá del parecido de familia que existe entre el Facundo y Los Sertones, cada una de estas obras enmarca un mundo de sentido y un relato que se encuentra en una tangente pero abre caminos a dos relatos perpendiculares. Es por ello que uno de los actuales traductores al alemán de la obra de Da Cunha, al trazar un paralelismo con la obra de Sarmiento, señala este (des)encuentro de la siguiente manera:

As duas quase-epopéias nacionais se complementam de modo singular, pois pertencem, ao nível do enredo e dos deslocamentos no espaço, a modelos diferentes, arquetípicos, ambos prefigurados em Homero. Pois Facundo, construído no seu núcleo narrativo como um romance de aventuras, tem alguma analogia com a trama da Odisséia, sendo o seu herói ao mesmo tempo um Ulisses, astuto e forte, embora também covarde e sanguinolento, que vagueia pelos pampas, e pretendente ilegítimo de uma Penélope coletiva, ou seja da Nação argentina. [...] Os Sertões pelo contrário segue a certa distância o esquema da llíada, os conselheiristas desempenhando o papel dos troianos e os soldados o dos gregos, uma guerra de sítio de meses, mas com antecedentes de décadas, entre os quais o rapto de uma Helena sertaneja, a esposa do Conselheiro, seduzida por um soldado, ato ilegítimo que desencadeou, ao nível da narrativa, as peregrinações de Antônio Mendes Maciel e sua transfiguração em Antônio Conselheiro, líder espiritual da população sertaneja (Zilly, 2001:sn).

Ahora bien, esta intertextualidad que atraviesa Los Sertones no se limita únicamente a aquellos trazos que anteceden o son contemporáneos al propio Da Cunha y su obra, sino que también puede rastrearse inclusive en la estela que este ensayo ofrece a la literatura y las ciencias sociales brasileñas y latinoamericanas. En este punto, el lector hispanoparlante puede conocer las incidencias de la rebelión de Canudos a través de la obra literaria de M. Vargas Llosa "La guerra del fin del mundo". Siendo una de las pocas novelas del autor peruano que se desarrolla fuera de su país, y originalmente destinada a ser el guion de una película, el libro de Vargas Llosa que apareció en 1981 no tendría entidad o razón de ser alguna de no existir las crónicas periodísticas que Da Cunha traspuso en Los Sertones, tal y como el propio autor nobel lo señala en el "Prólogo" escrito en el año 2000: "No hubiera escrito esta novela sin Euclides Da Cunha, cuyo libro Os Sertoes me reveló en 1972 la guerra de Canudos, a un personaje trágico y a uno de los mayores narradores latinoamericanos" (Vargas Llosa, 2008: 7).

Este fragmento marca claramente cómo la fascinación de Vargas Llosa es tanto por Canudos 
como por el propio Da Cunha, al punto tal de incorporar al ingeniero y periodista brasileño como el personaje principal de la novela. Como señala A. Mac Adam (1984:161), la epopeya de Da Cunha de ser escritor y a la vez testigo de los hechos, parece haber envalentonado a Vargas Llosa por incorporarlo a su novela. Sin embargo, Vargas Llosa no enviste al escritor brasileño de características extraordinarias, sino más bien todo lo contrario, al adjetivarlo como un periodista miope, torpe, feo y desgarbado, características que junto con la de romántico y desventurado podrían caracterizar al mismísimo Da Cunha en su epistolario de muerte el 15 de agosto de 1909. La trasposición de la experiencia personal de Da Cunha en la novela puede verse en detalles menores -pero de enorme significancia- como el hecho de que el propio autor brasileño no estuvo presente los últimos días del asedio a Canudos a raíz de una enfermedad, en tanto que el Da Cunha en La Guerra del fin del mundo, pierde sus anteojos en el clamor de sus últimos días como cronista, desdibujando así su testimonio de los sucesos que acaecen frente a sus ojos pero de los que no puede dar cuenta con nitidez.

Por último, como señala ajustadamente el propio Mac Adam (1984:163-164), Vargas Llosa no se circunscribe únicamente a corporeizar a Da Cunha como uno de los personajes de su novela, sino que también replica este hecho al introducir como uno de los personajes que también se dirige a Canudos a Galileo Gall “...un escocés que anda pidiendo permiso a la gente de Bahía para tocarles la cabeza" (Vargas Llosa, 2008:23), que tiene reminiscencias al escocés Robert Bontine Cunninghame Graham, el primer escritor en lengua inglesa en escribir sobre la guerra de Canudos. Este paralelismo adquiere fuerza ya que Vargas Llosa reescribe ciertos fragmentos de A brazilian Mystic, Being the life and Miracles of Antonio Conselheiro para volverlos parte del texto que enuncia Galileo Gall.

Entre los escritores y literatos brasileños, la intertextualidad con la obra Los Sertones puede verse emparentada en la obra de J. Guimarães Rosa Gran Sertón: veredas publicado en 1956. En este libro, al igual que en el de Da Cunha puede encontrarse la perturbación del autor por dar cuenta de la particularidad que adquiere la nación brasileña en el marco de este territorio desértico, aunque Da Cunha lo circunscribe a Canudos (en el norte de Bahía) y Guimarães Rosa al sur del estado de Bahía y su frontera con Goiás y Minas Gerais.

Asimismo, tal y como lo hiciera el propio Da Cunha al tener que apelar a una innumerable cantidad de términos que se ve compelido a definir para que resuene con toda su corporeidad la voz del hombre del sertón, los encargados de la traducción del libro de Guimarães Rosa al español en el año 2009, señalan que este autor utiliza casi 8000 palabras sin referencia en el diccionario de la lengua portuguesa, que llevó inclusive a que la especialista Nilce Sant'anna Martins escribiera un libro de 500 páginas llamado O léxico de Guimarães Rosa. Esto muestra en gran medida cómo ambos comparten el esfuerzo por recuperar el sonido y el sentido de la voz del sertanejo (Garramuño y Aguilar, 2009: 12).

Más allá de que tanto Da Cunha como Guimarães Rosa compartan esta atracción por el desierto bahiano, para este último el sertón es un cúmulo de valores éticos, una forma de vida, un esquema simbólico e interpretativo a partir del cual se desarrolla la acción y el comportamiento humano. En este sentido, como propone Custodia Sena (1998:27), el sertón que nos propone Guimarães Rosa no es el reverso de la cultura del litoral del sudeste brasileño, o el anverso del Brasil moderno, sino un Brasil en sí mismo que se resignifica una y otra vez de generación en generación, porque no solo el sertón está dentro nuestro, sino también como dice Guimarães Rosa "el sertón tiene muchos nombres".

Por último, una de las referencias donde la impronta de la obra de Da Cunha se torna visible y potente es en la propuesta del sociólogo y antropólogo pernambucano Gilberto Freyre, autor de célebres obras como Casa-Grande e Senzala: Formação da Família Brasileira sob o Regime da Economia Patriarcal (1933), Sobrados e Mucambos: Decadência do Patriarcado Rural e Desenvolvimento Urbano (1936) o Nordeste: A Influência da Cana sobre a Vida e a Paisagem do Nordeste no Brasil (1937), pero también un lector sesudo de la obra de Da Cunha como lo da cuenta su ensayo Perfil de Euclides e Outros Perfis de 1944. Al igual que el cronista de la rebelión de Canudos, Freyre se encuentra entrampado junto 
a la intelectualidad brasileña del primer tercio del siglo XX, en dar cuenta de los problemas brasileños.

Sin embargo, existe un contrapunto entre Freyre y Da Cunha; por ejemplo, para Freyre la extensión y movilidad de la colonia impide pensar como lo apuntara Los Sertones en una clara diferencia entre las experiencias del sur y del norte, o bien que sea posible sostener antropológicamente el determinismo biológico y geográfico del que parte Da Cunha, ya que es impreciso cuando no culturalmente erróneo (Nicolazzi, 2010:259). Sin embargo, este distanciamiento por parte de Freyre, no significa la pérdida de atracción por la empresa realizada por el propio Da Cunha, como puede verse claramente en la introducción que realiza Freyre al libro de Da Cunha Canudos (diarios de una expedición) publicado en 1939, del que reproducimos un fragmento a continuación:

...na descripção dos sertões, o scientista erraria em detalhes de geographia, de geologia, de botânica, de antropologia; o sociólogo, em pormenores de explicação e de diagnostico sociaes do povo sertanejo. Mas para o redimir dos erros de technica, havia em Euclydes da Cunha o poeta, o propheta, o artista cheio de intuições geniaes (Freyre, 1939: 11 citado por Nicolazzi, 2010:263).

En definitiva, todas esta intertextualidad que se entrecruza en Los Sertones lo convierten en un texto con múltiples vías de entradas y vías de salida, dable de ser recuperado en tanto texto épico literario, como documento histórico antropológico, o bien como piedra de toque para construir simbólicamente los lindes del ser y la nación.

\section{El paratexto como fin}

La fascinación por la policromática inconmensurabilidad de Brasil es una constante que puede encontrarse reiterada no solo en los relatos de viajeros que atravesaron este país durante el siglo XVIII, XIX y XX como Stefan Zwaig, sino también en el denodado esfuerzo de los intelectuales y pensadores latinoamericanos $y$ brasileños como Euclides Da Cunha. El atrevimiento que aquí hemos realizado por recuperar en español Los Sertones, en tanto monumental obra que pre configura los problemas brasileños contemporáneos, es un arresto por colocar un título, un prefacio, un índice, o simplemente un paratexto más, en el largo epistolario de la reflexión ensayística sobre Latinoamérica, dado que muchas veces se ha hecho de Brasil un desconocido, un sertón en el más puro sentido de Da Cunha.

Poder inscribir la obra de Da Cunha en el marco de su época, tratando de desmenuzar su complejidad y extensión, así como también encontrando los rastros de su diálogo con y en innumerables autores, es un esfuerzo que requirió volver una y otra vez al punto de inicio de esta filigrana que es Los Sertones, dado que las huellas en la arena de esta obra se desdibujaban rápidamente. Sin embargo, aunque Penélope teja y desteja el manto para el Rey Laertes sin dejar rastros de lo que fue y dejó de ser, o el listón con el cual aventurarse dentro del laberinto del Fauno se rasgue o enrede, las marcas que dejó esta tarea, esta búsqueda, difícilmente se perderán. Al igual que le sucedió al propio Da Cunha en la sumersión en los sertones bahianos, nuestra inmersión en Los Sertones fue una empresa que dejó vestigios, interrogantes y reflexiones que nunca podrán ser finales o concluyentes.

Tal vez lo único que pueda enunciarse en el momento final de este ensayo de reflexión, sea reproducir la misma sensación de vértigo que tuviera el autor en su página final, por saber que mil cosas quedan por decir y muchas más por recuperar de esta inagotable obra, por entender que siempre las primeras aproximaciones a una gran texto generan un mirada enceguecida y voraz, o simplemente por avizorar que los esfuerzos del final son siempre volver a las añoranzas del principio.

Cerremos este libro. Canudos no se rindió. Ejemplo único en toda la historia, resistió hasta el agotamiento completo (...) Esta página [final] siempre la hemos imaginado profundamente emocionante y trágica; pero cerrémosla vacilante y sin brillos. Hemos visto, como quien escaló una montaña altísima. En lo alto, a la par de una perspectiva mayor, el vértigo... (Da Cunha, 2012: 422 y 423). 


\section{REFERENCIAS BIBLIOGRÁFICAS}

CANDIDO, A. (2000). Literatura e cultura de 1900 a 1945. En: Literatura e sociedade. São Paulo: T. A. Queiroz.

DA CUNHA, E. (2012) Los Sertones. Campaña de Canudos. Buenos Aires: Fondo de Cultura Económica. 2a ed.

DE OLIVEIRA, R. D. (2002). Euclides da Cunha, Os Sertões e a invenção de um Brasil profundo. Revista Brasileira de História, 22(44). pp. 511-537.

FERNANDES, F. (1977). A sociología no Brasil. Contribuição para o estudo de sua formação e desenvolvimento. Petrópolis: Vozes

FERNÁNDEZ URIBE, C. A. (2004). Hipólito Taine: la obra de arte como hija de su tiempo. Artes, la Revista, 3(6). pp. 49-63.

GARRAMUÑO, F. (2012) Pueblo sin Estado: Los Sertones y el imaginario moderno. En: DA CUNHA, E. Los Sertones. Campaña de Canudos. Buenos Aires: Fondo de Cultura Económica. $2^{\text {a }}$ ed.

GARRAMUÑO, F;: DE AGUILAR, G (2009) Introducción. En: GUIMARÃES ROSA, J. (2009). Gran Sertón: Veredas. Buenos Aires: Adriana Hidalgo Editora.

GUIMARÃES ROSA, J. (2009). Gran Sertón: Veredas. Buenos Aires: Adriana Hidalgo Editora.

HARDMAN, F. F. (1996). Brutalidade antiga: sobre história e ruína em Euclides. Estudos avançados, 10(26). pp. 293-310.

MAC ADAM, A. (1984). Euclides da Cunha y Mario Vargas Llosa: Meditaciones intertextuales. Revista iberoamericana, 50(126). pp. 157-164.

MURARI, L. (2007). Brasil, ficção geográfica: ciência e nacionalidade no país d'Os Sertões. Rio de Janeiro: Annablume.

NICOLAZZI, F. (2010). À sombra de um mestre: Gilberto Freyre leitor de Euclides da Cunha. História. 29 (1). pp. 54-277.

ORTIZ, R. (1990). Notas sobre as ciências sociais no Brasil. Novos estudos CEBRAP, 27. pp. 163-175.

VARGAS LLOSA, M. (2008). La guerra del fin del mundo. Buenos Aires: Alfaguara.

VASQUEZ, P. (2003). O Brasil na fotografia oitocentista. São Paulo: Metalivros.

VENTURA, R. (1997). Canudos como cidade iletrada. Revista de antropologia, 40 (1). pp. 165-182.

ZILLY, B (1999) Sertão e nacionalidade: formação étnica e civilizatória do Brasil segundo Euclides da Cunha. Estudos: Sociedade e Agricultura, 12. pp. 5-45.

ZILLY, B (2001). De sertões, desertos e espaços incivilizados. Rio de Janeiro: Faperj-Ed. Mauad. 